\title{
Inductor Disc CFD Analysis for VAWT
}

\section{Análisis CFD de Discos Inductores para Turbina Eólica de Eje Vertical}

\author{
MARIN-TELLEZ, Gerardo Javier†*, LÓPEZ-GARZA, Víctor, MARIN-TELLEZ, Paulina and \\ SANTIBAÑEZ-MALDONADO, Adrián
}

Universidad Michoacana de San Nicolás de Hidalgo, Mechanical Engineering Faculty

ID $1^{\text {st }}$ Author: Gerardo Javier, Marin-Tellez / ORC ID: 0000-0002-2613-0570, CVU CONACYT ID: 1051543

ID $1^{\text {st }}$ Co-author: Víctor, López-Garza / ORC ID: 0000-0001-9090-9119, Researcher ID Thomson: H-6969-2018, Open ID: 107470673007841597382, CVU CONACYT ID: 554311 ID $2^{\text {nd }}$ Co-autor: Paulina, Marin-Tellez / ORC ID: 0000-0003-2966-3409 Researcher ID Thomson G-2113-2019, CVU
CONACYT ID: 928539

ID $3^{\text {rd }}$ Co-autor: Adrián, Santibañez-Maldonado / ORC ID: 0000-0003-2090-9556, CVU CONACYT ID: 1009460

DOI: $10.35429 / J T E N .2021 .16 .5 .1 .11$

Received July 14, 2021; Accepted October 30, 2021

\begin{abstract}
This work shows the computational simulation of the fluid dynamics of inductor discs (patent pending reception number MX/E/2021/002395) applied to vertical axis wind turbines (VAWT). These inductor discs have a unique and innovative design that can be classified as wind concentrators. The purpose of these devices is to increase wind velocity at the wind turbine entrance; this increase in velocity exponentially boosts the mechanical power of the turbine, according to Betz's theory, increasing the electrical energy production of the turbine and, at the same time, reducing its dimensions. The objective of this investigation is to carry out the fluid dynamic simulation (CFD) of two of the inductor disc geometries: an elliptical one and a truncated conical one, varying the entrance wind velocities of the VAWT from $3 \mathrm{~m} / \mathrm{s}$ to $12 \mathrm{~m} / \mathrm{s}$. The proposed methodology consists of employing a CFD software (ANSYS) to model the two inductor disc geometries and extract them from a static control volume. Mesh this volume, establish boundary conditions, and vary wind velocities to carry out the fluid dynamic analysis. Finally, the obtained velocities are compared at different representative points of both geometries.
\end{abstract}

Simulation, VAWT, Optimization

\begin{abstract}
Resumen
En el presente trabajo, se muestra la simulación computacional de dinámica de fluidos de unos discos inductores (patente en trámite folio de recepción MX/E/2021/002395) con aplicación en turbinas eólicas de eje vertical. Los discos inductores tienen un diseño único e innovador y se pueden clasificar en la categoría de concentradores de eólicos. La finalidad de estos dispositivos es aumentar la velocidad del viento en la entrada de la turbina eólica; con el aumento de esta velocidad la potencia mecánica de la turbina se incrementa exponencialmente de acuerdo con la teoría de Betz, aumentando así la producción de energía eléctrica de la turbina y al mismo tiempo se reducen las dimensiones la misma. El objetivo de esta investigación es realizar la simulación fluidodinámica computacional (CFD) de dos geometrías de discos inductores; una elíptica y otra de cono truncado, variando la velocidad de entrada del viento a la turbina eólica vertical, desde $3 \mathrm{~m} / \mathrm{s}$ hasta $12 \mathrm{~m} / \mathrm{s}$. La metodología propuesta consistió en emplear un software CFD (ANSYS) para modelar las dos geometrías de los discos de inducción y extraerlas de un volumen estático de control. Mallar este volumen, establecer las condiciones de frontera y variar las velocidades del viento para realizar el análisis de dinámica de fluidos. Finalmente se comparan las velocidades obtenidas en diferentes puntos representativos de ambas geometrías.
\end{abstract}

Simulación, Turbina eólica de eje vertical, Optimización

Citation: MARIN-TELLEZ, Gerardo Javier, LÓPEZ-GARZA, Víctor, MARIN-TELLEZ, Paulina and SANTIBAÑEZMALDONADO, Adrián. Inductor Disc CFD Analysis for VAWT. Journal of Technological Engineering. 2021. 5-16: 1-11

\footnotetext{
* Correspondence to Author (e-mail: 1422986a@umich.mx)

$\dagger$ Researcher contributing as first author.
} 


\section{Introduction}

Renewable energy is the present and future of worldwide electrical energy production. The wind-energy industry is one of the fastestgrowing renewable energy technologies and has positioned itself as the second largest renewable energy source of electrical power generation in the world (GWEC, 2019; Subsecretaría de Energía Eléctrica, 2019). Wind turbines can be classified by the orientation of their rotational axes as horizontal axis wind turbines (HAWT) and vertical axis wind turbines (VAWT). A vertical axis wind turbine is a wind machine whose rotational axis is perpendicular to the wind's direction (Presses Internationales Polytechnique, 2002; Yusof \& Mohamed, 2020).

Vertical axis wind turbines have several advantages when compared to horizontal axis wind turbines, such as: they are better suited for turbulent winds, changing wind directions, and low-velocity winds. In addition, they have no need of an orientation system, are less noisy, and have a simpler and more compact design (Presses Internationales Polytechnique, 2002; Yusof \& Mohamed, 2020).

Vertical axis wind turbines have efficiencies of between 40-50\%; this percentage is below the theoretical efficiency of a wind turbine. Therefore, there exists additional potential in bettering this type of turbine so as to increase its efficiency (Yusof \& Mohamed, 2020). To better utilize the wind resource in wind turbines, devices called wind concentrators are used. These devices increase the velocity of wind flow at the turbine rotor entrance by employing a specific geometrical configuration that guides the flow upstream or downstream of the device. The purpose of wind concentrators is to achieve a drastic reduction in rotor size while maintaining a low manufacturing cost (García \& García, 2012; Hau, 2005).

This present work shows the CFD simulation of inductor discs applied to vertical axis wind turbines. The inductor discs can be classified as wind concentrators, as their objective is to homogenize wind current lines that affect the turbine to increase wind velocity and therefore, achieve a greater energy production in the turbine by means of a passive mechanical device. It must be emphasized that the inductor discs have a unique and innovative design.
This work has as its objective to evaluate and compare two inductor disc geometries, one elliptical, and the other truncated cone, applied to a low-capacity wind turbine using ANSYS software CFX module.

The first section of the article gives a brief introduction to the historical development of vertical axis wind turbines and mentions the most common wind concentrators, as well as the concept of wind turbine potency, to provide the reader with context.

Afterwards, the employed methodology is shown in a general manner, and the next section carries out the dynamic fluid simulation done by ANSYS software CFX module.

The computational fluid dynamics simulations show the two inductor disc geometries which were analyzed, elliptical and truncated cone, as well as the used control volume; they show the mesh in detail, describe the boundary conditions, and present the analyzed wind velocities. Finally, the wind velocity results for each geometry are shown.

\section{Wind Turbines}

\subsection{Historical Development of Vertical Axis Wind Turbines}

The first known practical windmills were built in Sistan in the seventh century and were the first vertical axis windmills. However, it was not until the Cold War and the energetic crisis of 1970 that wind turbines were presented as a competitive source for electrical power generation (Subsecretaría de Energía Eléctrica, 2019; Yusof \& Mohamed, 2020).

In 1922, Finnish architect Sigurd Johannes Savonius invented the Savonius turbine; this is the simplest vertical axis wind turbine that exists and is characterized, principally, by its $\mathrm{S}$-shaped blade. The Savonius turbine is a drag device and tends to produce a high starter pair; therefore, it reduces shear velocity and requires a low-velocity wind to start rotating; in addition, it has a lower efficiency than other turbines. It should be noted that conventional Savonius turbines are not suited for electrical power generation due to their inability to rotate faster than the wind (Hau, 2005; Yusof \& Mohamed, 2020). 
In 1925, French engineer Georges Jean Marie Darrieus invented the Darrieus turbine; this turbine had curved blades that were positioned around a rotating vertical axis. The Darrieus-type turbine showed greater potential than the Savonius, and thus was the center of technological development (Hau, 2005; Yusof \& Mohamed, 2020).

Two principal configurations for the Darrieus turbine were developed: straight blades and curved blades. The curved-bladed configuration evolved from a conventional cable-fastening base to a fixed tower base, and finally, to a vertical cantilevered base (Hau, 2005; Yusof \& Mohamed, 2020).

Meanwhile, straight-bladed configurations underwent multiple variations: a changeable geometry, the Musgrove rotor; a changeable pace, the Giromill rotor; a changeable diamond-rotor configuration, Delta, in either V-shape or Y-shape. However, they did not prosper, due to the high specific cost of energy (Hau, 2005; Yusof \& Mohamed, 2020).

The Musgrove rotor survived and evolved into a configuration in which the blades formed an $\mathrm{H}$-shape, with straight blades and fixed pace, simply named $\mathrm{H}$ rotor. The $\mathrm{H}$ rotor also underwent variations: articulated, inclined, and helicoidal $\mathrm{H}$ rotors. There have also been a few hybrid designs using Savonius and Darrieus rotors (Hau, 2005; Yusof \& Mohamed, 2020).

\subsection{Wind-Energy Concentrators}

The basic idea of a wind-energy concentrator is to increase potential performance in relation to rotor sweep area by employing a static structure (Hau, 2005).

This idea can be traced back to the first days of windmill history, as shown by ancient windmill drawings from the Middle East. The most studied and known wind concentrators are as follows (Hau, 2005; Shonhiwa \& Makaka, 2016):

Conducted rotor: this is the simplest method and consists of confining the rotor in a duct. The potential coefficient that can be obtained by this method is 0.66 (Hau, 2005; Shonhiwa \& Makaka, 2016).
Diffuser-duct turbine: as its name indicates, a funnel-shaped duct is placed behind the rotor, creating a diffuser. It can reach a potential coefficient of 0.75 (Hau, 2005).

Vortex tower: in a tower with adjustable slots placed in the cylinder liner, the wind flows tangentially towards the interior of the duct, where an air vortex, like a tornado, is formed. Due to the low pressure at the center of the vortex, the air is sucked from the bottom part of the tower into the duct, propelling in that manner a turbine with a diameter of approximately onethird of the tower's diameter (Hau, 2005).

\subsection{Wind Turbine Potency}

The potency generated by a wind turbine is determined by the following equation:

$$
P=\frac{1}{2} C_{p} A \rho_{\text {aire }} V^{3}
$$

Where $P$ is the mechanical potency of the turbine, $C_{p}$ is the potential coefficient specific to the turbine, $A$ is the cross-sectional area of the turbine through which the wind flows, $\rho$ is the air density, and $\mathrm{V}$ is the wind velocity before entering the rotor (Presses Internationales Polytechnique, 2002; Shonhiwa \& Makaka, 2016).

As shown in equation 1 , wind turbine potency depends on 4 factors ( $C_{p}, A$, $\rho_{\text {aire }}$ and $V$ ); in each case, it is directly proportional to them; that is, if we increase any of these factors, the potency of the turbine also increases.

$C_{p}$ is specific to each turbine model; $\rho_{\text {air }}$ depends on the site where the turbine will be installed and varies, principally, depending on the elevation and the annual average temperature of the site; in a similar manner, $A$ depends on the shape of the turbine; and $V$ depends on many factors, such as topographical and climatological ones. In general, $V$ is the most important factor, since its value has a cubed implication on the potency; for example, if the wind velocity doubles, the potency increases $800 \%$ (Presses Internationales Polytechnique, 2002; Shonhiwa \& Makaka, 2016). To emphasize even further the importance of wind velocity, according to Betz's theory, rotor diameters are inversely proportional to wind velocity. 
Therefore, rotor diameter sizes and wind turbines significatively decrease when wind velocity increases (Presses Internationales Polytechnique, 2002; Shonhiwa \& Makaka, 2016).

\section{Methodology}

Overall, the followed methodology was to model the two proposed inductor disc geometries (elliptical and truncated cone) using the DesignModeler module in ANSYS Workbench software. The CFX module of ANSYS software was used to analyze the computational fluid dynamics; a control volume was modelled and both geometries were meshed. After meshing, boundary conditions were established, including different wind velocities. Finally, the simulation was run, and the results were analyzed. See Graph 1.

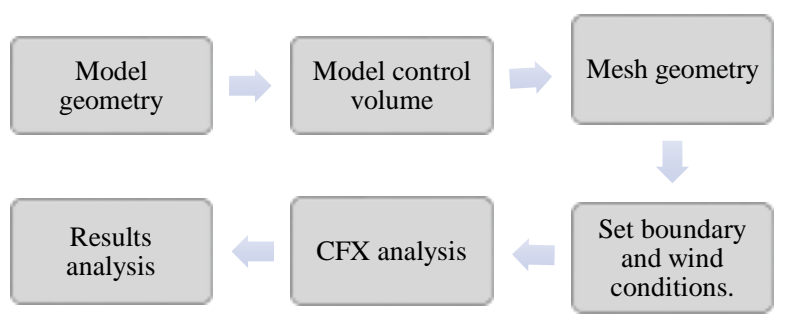

Graph 1 General methodology

Source: Authors' Own Creation

\section{Computational Fluid Dynamics Simulation}

\subsection{Inductor Disc Geometries}

The first evaluated induction disc geometry has an elliptical shape; the second geometry has a truncated-cone shape. To compare these geometries, the same diameter was considered, 2.8 times greater than the turbine diameter (wind turbine diameter $2.3 \mathrm{~m}$ ), and the cross-sectional area where the turbine was placed was also the same in both geometries, shown as a dark gray color in Figure 1. The narrowest section in the shaded area is $1.6 \mathrm{~m}$, slightly taller than the wind turbine blade height (blade height $1.5 \mathrm{~m}$ ). To compare the performance of the inductor discs, these were designed in such a way that the reduction area occasioned by each of these geometries, corresponding to the cross-sectional area of the inductor discs at the frontal face of the control volume, was the same. This is represented graphically in Figure 1.
A big-enough computational domain was employed, to prevent the walls from being too close to the discs and affecting the development of wind flow. Deducting the cross-sectional disc area from the control volume frontal face area, the percentage of free area through which the wind can circulate is $97.9 \%$, shown as a shaded area in Figure 2.

a)

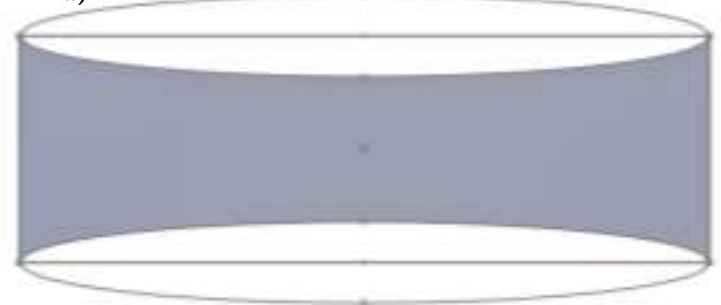

b)

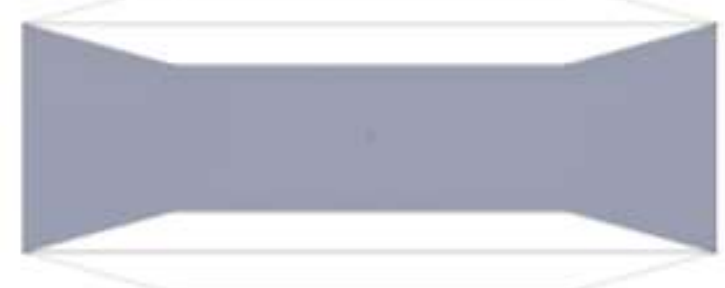

Figure 1 Induction cross-sectional areas of the evaluated geometries. a) Elliptical b) Truncated cone Source: Authors' Own Creation
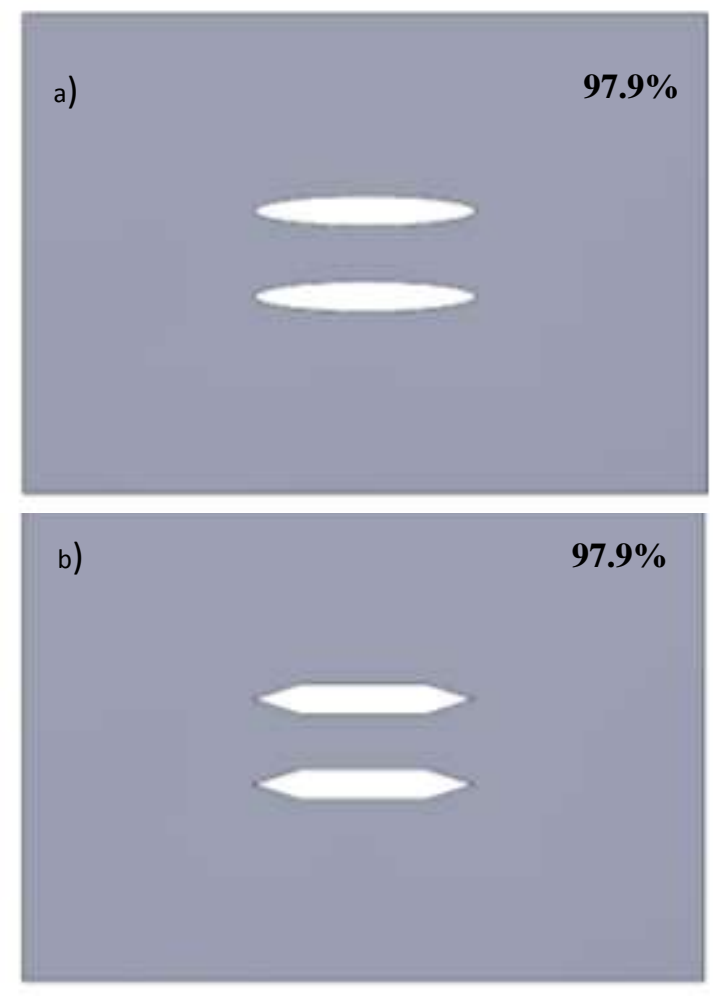

Figure 2 Representation of reduction area percentage. a) Elliptical. b) Truncated cone Source: Authors' Own Creation 


\subsection{Control Volume}

A static volume was modelled, comprising of a rectangular prism $22 \mathrm{~m}$ wide by $20 \mathrm{~m}$ high by 30 $\mathrm{m}$ long.

During the simulation, the wind flows through the smaller faces of the rectangular prism (Face A and Face B); the inlet face is closest to the wind turbine, Face A, located $10 \mathrm{~m}$ from the center of the rotor. The furthest face is the outlet face, Face B, located $20 \mathrm{~m}$ from the center of the rotor; the intention of having a greater length downstream is to appreciate the formation of tailwinds after having passed through the discs. See Figure 3.

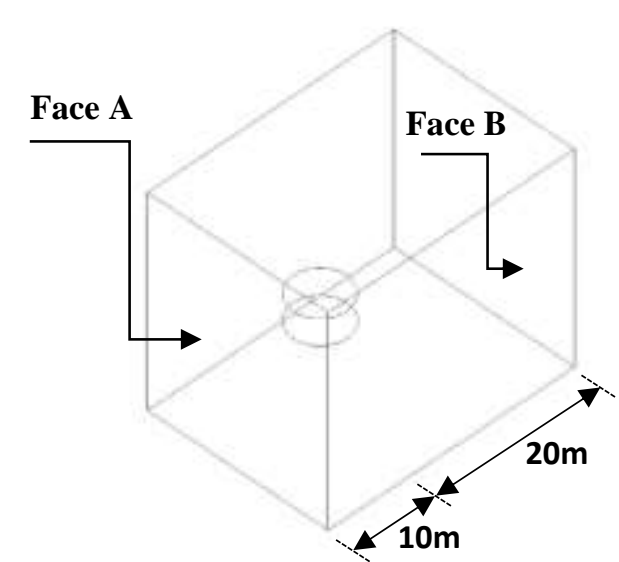

Figure 3 Control volume

Source: ANSYS (Academics)

\subsection{Mesh}

A non-structured mesh with tetrahedral and triangular-prism elements was used in both geometries. The tetrahedral elements predominate, and the triangular-prism elements were inflated around the zone of the inductor discs as shown in Figures 4-7.

A mesh refinement was used in both geometries around the induction discs, using the influence sphere method; the center of the sphere corresponds to the center of the induction discs in the middle of the height that separates them.

The elliptical geometry mesh has approximately 3.7 million elements, while the truncated-cone geometry mesh has approximately 3.6 million elements.

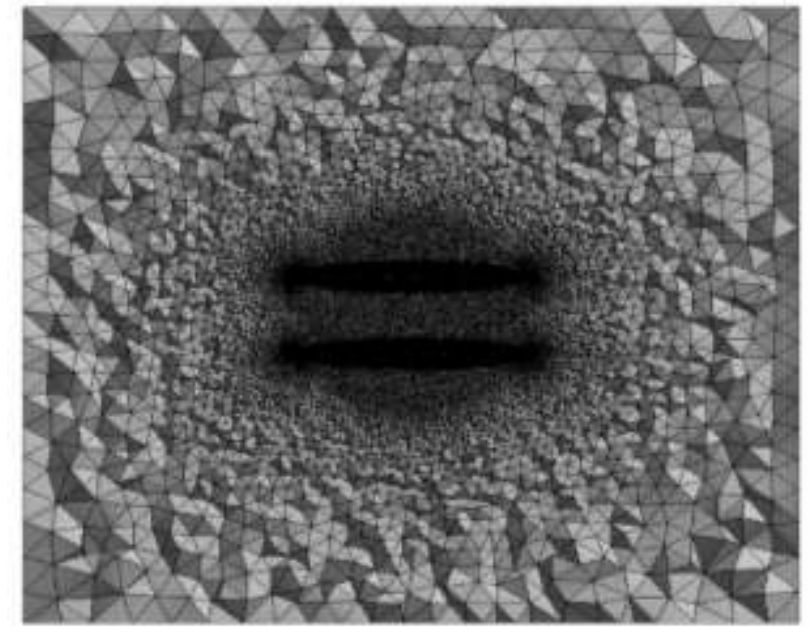

Figure 4 Cross section of elliptical geometry mesh Source: ANSYS (Academics)

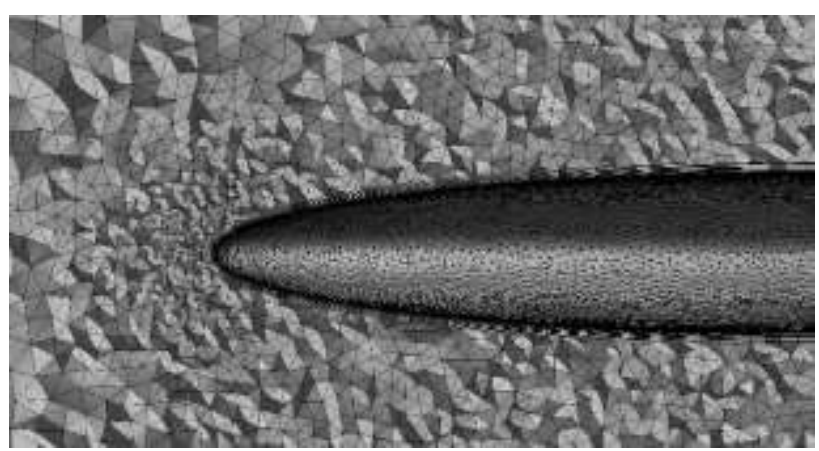

Figure 5 Refinement detail in induction disc zone of elliptical geometry. Source: ANSYS (Academics)

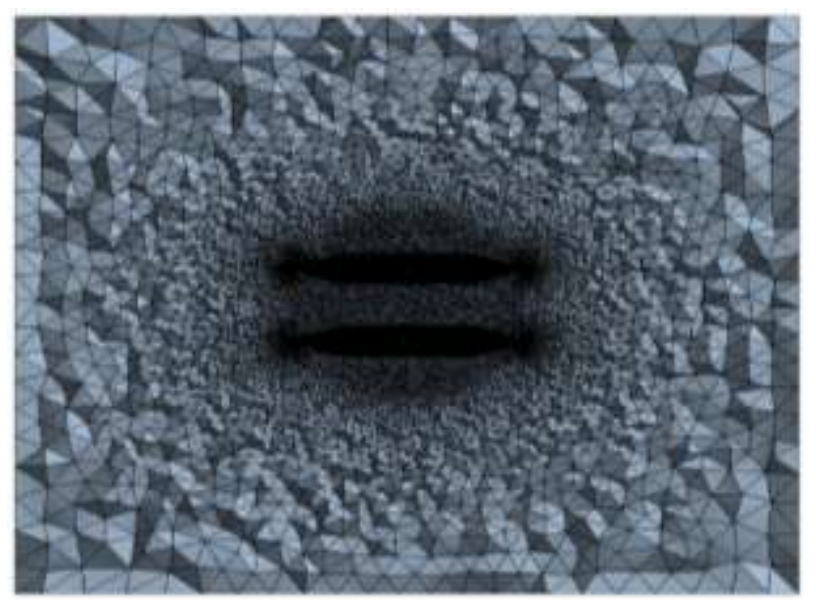

Figure 6 Cross section of truncated-cone geometry mesh. Source: ANSYS (Academics)

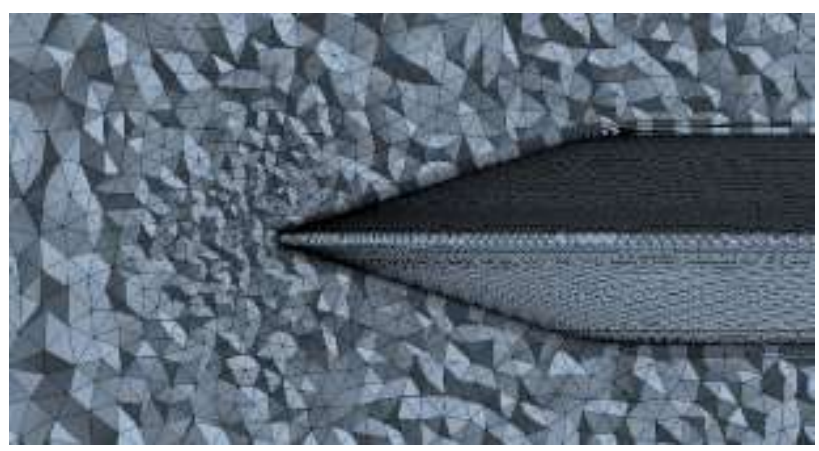

Figure 7 Refinement detail in induction disc zone of truncated-cone geometry. Source: ANSYS (Academics).

MARIN-TELLEZ, Gerardo Javier, LÓPEZ-GARZA, Víctor, MARINTELLEZ, Paulina and SANTIBAÑEZ-MALDONADO, Adrián Inductor Disc CFD Analysis for VAWT. Journal of Technological Engineering. 2021 


\subsection{Boundary conditions}

Face A was defined as the inlet of a constantvelocity and uniform wind; Face $B$, as the outlet of wind flow at atmospheric pressure; and the wind velocities at the adjacent faces were identical in magnitude and direction to the inlet velocity.

Wind velocity varied in a range from 3 to 12 $\mathrm{m} / \mathrm{s}$. Standard air conditions for temperature, density, and dynamic viscosity were considered.

\section{Results}

The obtained data from the simulation are the increases in wind velocity due to the induction discs. Twenty-one representative points were sampled across three planes; in other words, seven points per plane: Frontal Disc (DF), Posterior Disc (DP), Frontal Rotor (RF), Posterior Rotor (RP), Left Rotor (RI), Right Rotor (RD), and Center (C).

The central plane is in the middle of the distance between the inductor discs; the top plane is in the space that separates the induction disc and the top part of the wind turbine rotor: the bottom plane is in the space that separates the induction disc and the bottom part of the wind turbine rotor. See Figures 8 and 9.

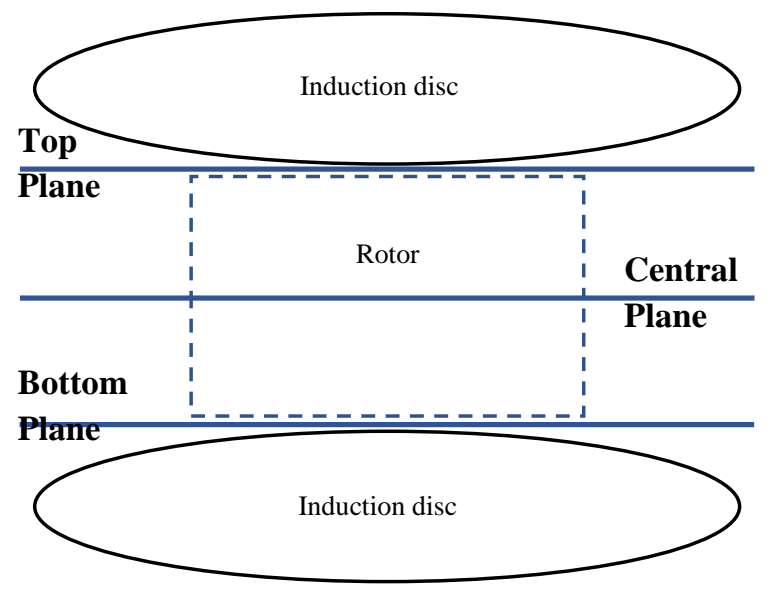

Figure 8 Cross-sectional view of used reference planes Source: Authors' Own Creation

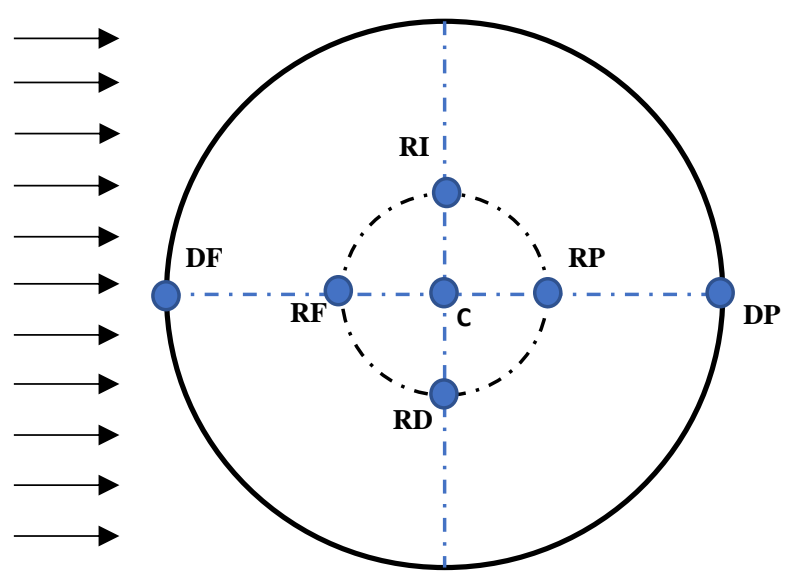

Figure 9 Top view of used reference planes Source: Authors' own creation

In Figures 10 and 11, the velocity contours for the induction discs with elliptical geometry are shown, at an inlet velocity of 12 $\mathrm{m} / \mathrm{s}$.

In Figures 12 and 13, the velocity contours for the induction discs with truncatedcone geometry are shown, at an inlet velocity of $12 \mathrm{~m} / \mathrm{s}$.

It can be observed that, in fact, the wind accelerates in a much more homogeneous manner with elliptical inductor discs, since with truncated-cone ones, there are concentration zones.

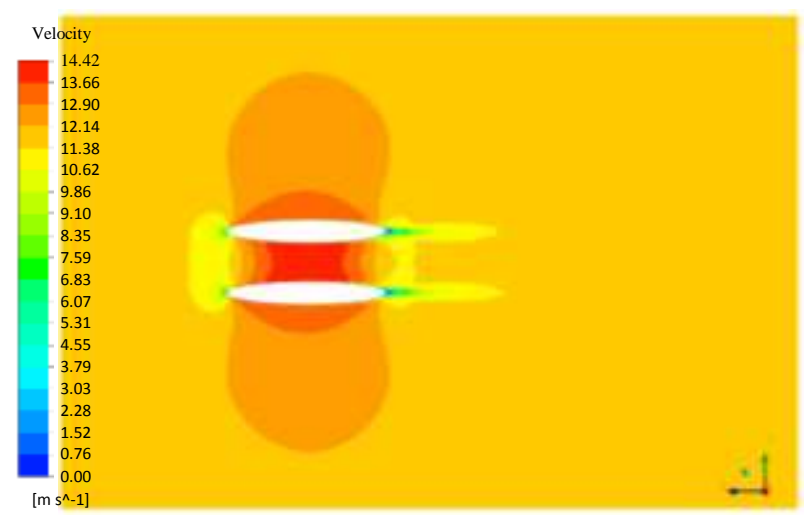

Figure 10 Wind velocity contours perpendicular to lateral face of elliptical geometry. Inlet wind velocity $12 \mathrm{~m} / \mathrm{s}$ Source: ANSYS (Academics) 


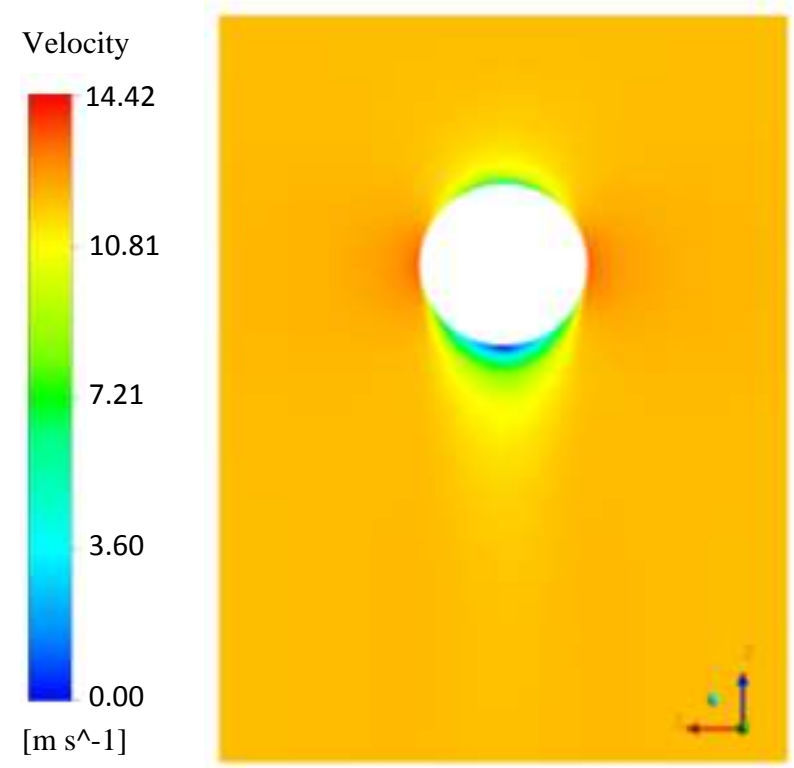

Figure 11 Wind velocity contours perpendicular to top face of elliptical geometry. Inlet wind velocity $12 \mathrm{~m} / \mathrm{s}$ Source: ANSYS (Academics)

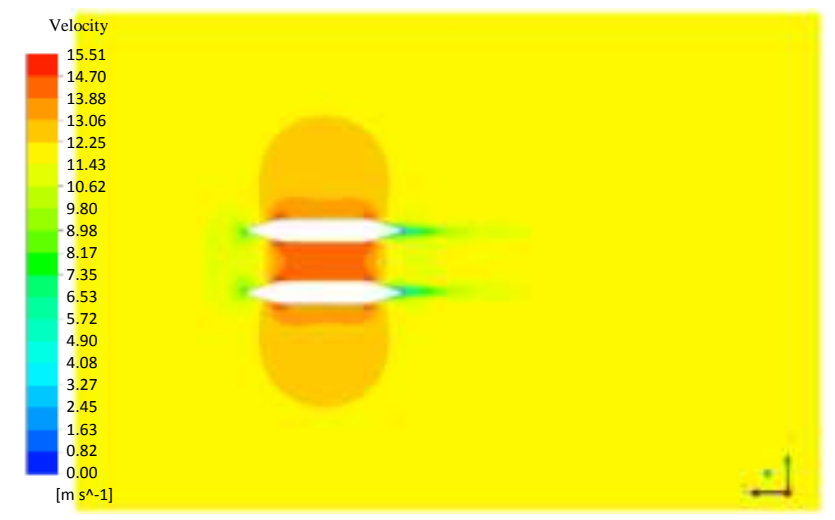

Figure 12 Wind velocity contours perpendicular to lateral face of truncated cone geometry. Inlet wind velocity 12 $\mathrm{m} / \mathrm{s}$. Source: ANSYS (Academics)

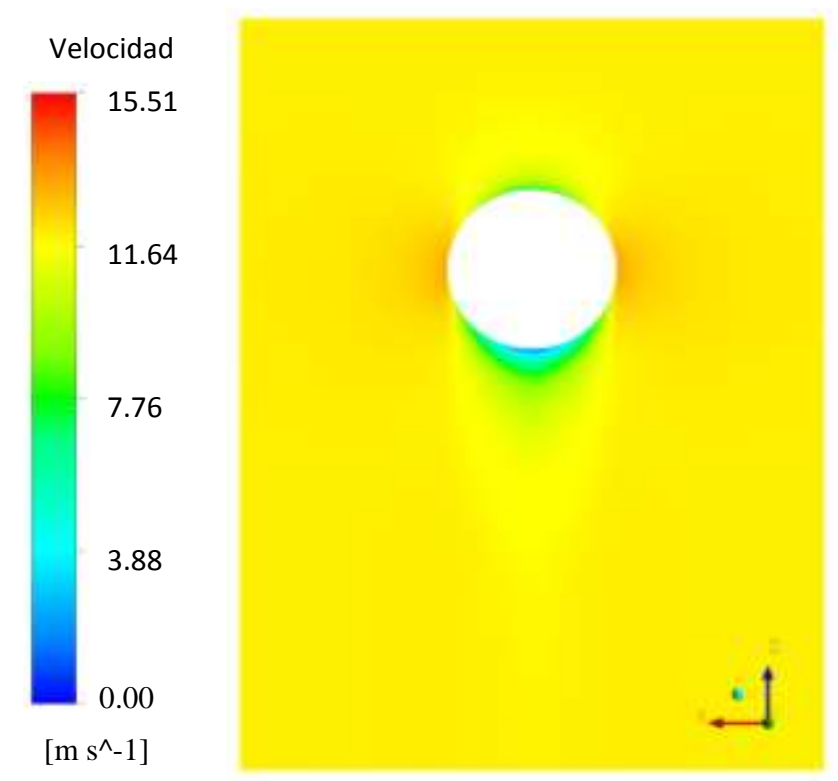

Figure 13 Wind velocity contours perpendicular to top face of truncated cone geometry. Inlet wind velocity 12 $\mathrm{m} / \mathrm{s}$

Source: ANSYS (Academics)
In Graphs 2-10, the results for the discs with truncated-cone geometry are shown in orange, and the results for the discs with elliptical geometry are shown in blue.

In Graphs 2-5, the data for wind velocity at each of the seven points in each plane for inlet velocities of 3,6, 9, and $12 \mathrm{~m} / \mathrm{s}$ are shown. The first five points, which are $\mathrm{DF}, \mathrm{RF}, \mathrm{C}, \mathrm{RP}$, and $\mathrm{DP}$, are ordered in such a way that allows for the following of the changes in wind velocity, since these points are located along the plane that is perpendicular to the wind face; see Figure 10 and Figure 12. The last two points pertain to where the rotor blades would be located; see Figure 9. The bars in Graphs 2-5 are ordered so that, along the central plane, the data for the elliptical discs are shown, and then, along the same plane, the data for the truncated-cone discs.

Based on Graphs 2-5, it can be observed that the wind velocity tendencies are practically identical in both top and bottom planes at their respective points (DF, DP, RF, RP, RI, RD, and C). This is to be expected due to the geometrical symmetry of the discs in relation to the central plane and the constant and uniform inlet velocity. It can also be observed that the velocity varies in greater measure along the central plane.

In the same manner, Graphs 2-5 are representative of the model, since the pattern shown is preserved for the missing velocities of $4,5,7,8,10$, and $11 \mathrm{~m} / \mathrm{s}$.

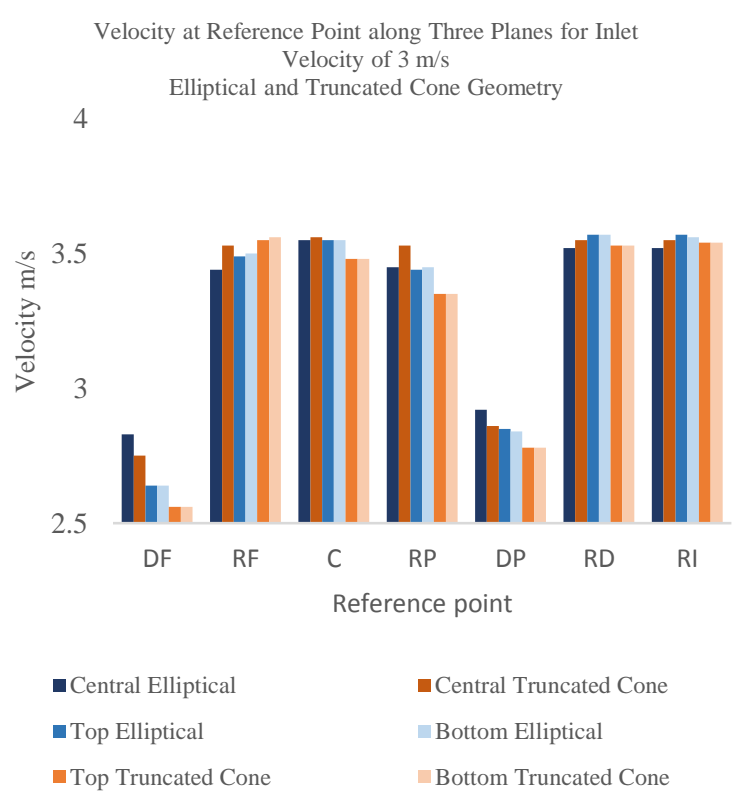

Graph 2 Velocity at each reference point along the three planes for an inlet velocity of $3 \mathrm{~m} / \mathrm{s}$, elliptical and truncated cone geometries

Source: Authors' Own Creation

MARIN-TELLEZ, Gerardo Javier, LÓPEZ-GARZA, Víctor, MARINTELLEZ, Paulina and SANTIBAÑEZ-MALDONADO, Adrián. Inductor Disc CFD Analysis for VAWT. Journal of Technological Engineering. 2021 


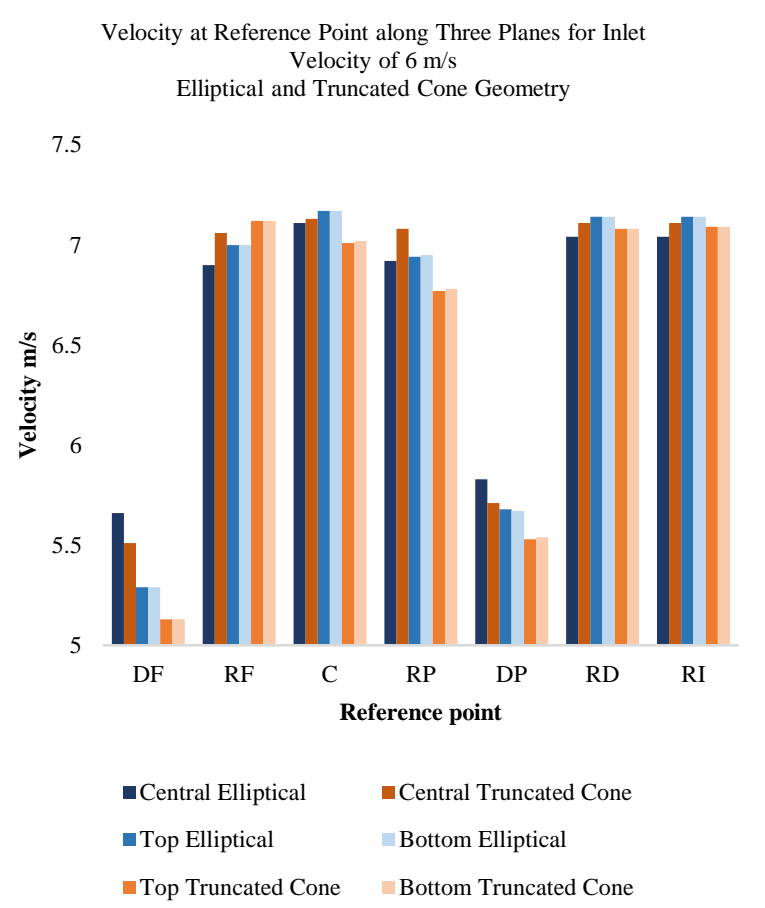

Graph 3 Velocity at each reference point along the three planes for an inlet velocity of $6 \mathrm{~m} / \mathrm{s}$, elliptical and truncated cone geometries

Source: Authors' Own Creation

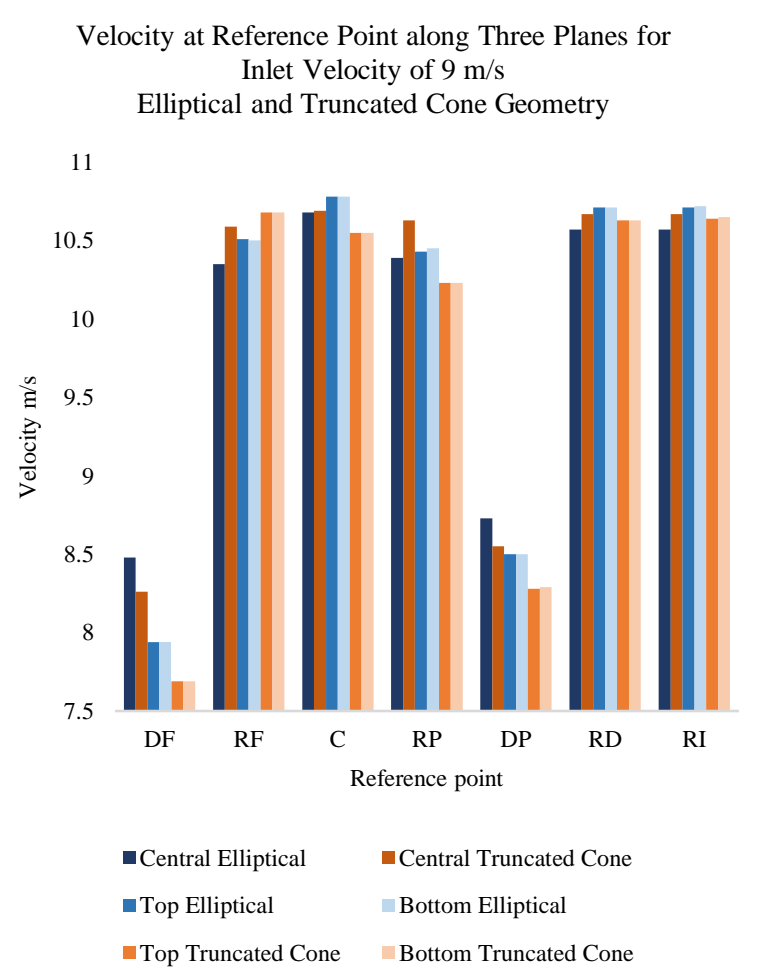

Graph 4 Velocity at each reference point along the three planes for an inlet velocity of $9 \mathrm{~m} / \mathrm{s}$, elliptical and truncated cone geometries

Source: Authors' Own Creation

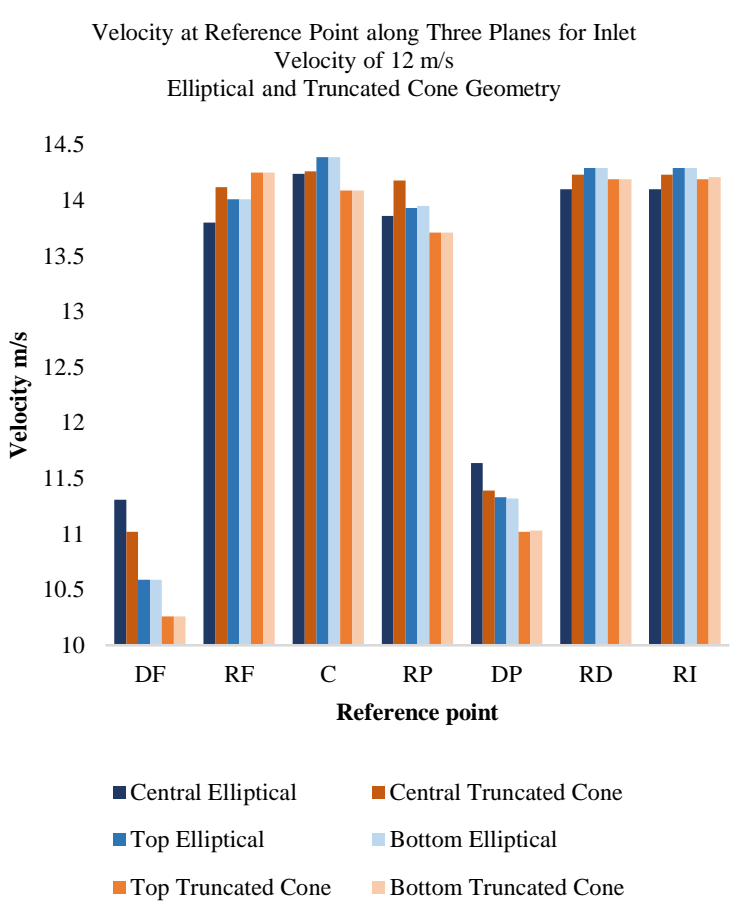

Graph 5 Velocity at each reference point along the three planes for an inlet velocity of $12 \mathrm{~m} / \mathrm{s}$, elliptical and truncated cone geometries

Source: Authors' Own Creation

In Graphs 6-8, the behavior of the velocity as it passes through the discs is analyzed in greater detail (see Figures 10 and 12), comparing the two geometries along the top (Graph 6), central (Graph 7), and bottom (Graph 8) planes. Graphs 6-8 are characteristic to the model, since the pattern repeats itself for the other velocities; an inlet velocity of $12 \mathrm{~m} / \mathrm{s}$ was used so that these coincide with the velocity in Figures 10-13.

In Graphs 6-8, it can be observed with greater detail the practically identical behavior between the top and bottom planes due to symmetry.

The elliptical geometry follows the same pattern in wind velocity change along the three planes (top, central, and bottom), increasing up to the central point (C) and subsequently decreasing until exiting the disc (DP). In the truncated-cone geometry, however, a different pattern along the central plane is observed, where there is an abrupt increase between points DF and RF; afterwards, a slighter increase (between RF and RP); and finally, an abrupt decrease between RP and DP; in contrast, along any of the other two planes (top or bottom), this behavior is inverted, as there is an abrupt increase between points DF and RF, but then a slow decrease between RF and RP, and finally, an abrupt decrease between RP and DP.

MARIN-TELLEZ, Gerardo Javier, LÓPEZ-GARZA, Víctor, MARINTELLEZ, Paulina and SANTIBAÑEZ-MALDONADO, Adrián. Inductor Disc CFD Analysis for VAWT. Journal of Technological Engineering. 2021 
For the most part, it can be observed that the truncated-cone geometry has more abrupt changes in wind velocity compared to the elliptical geometry.

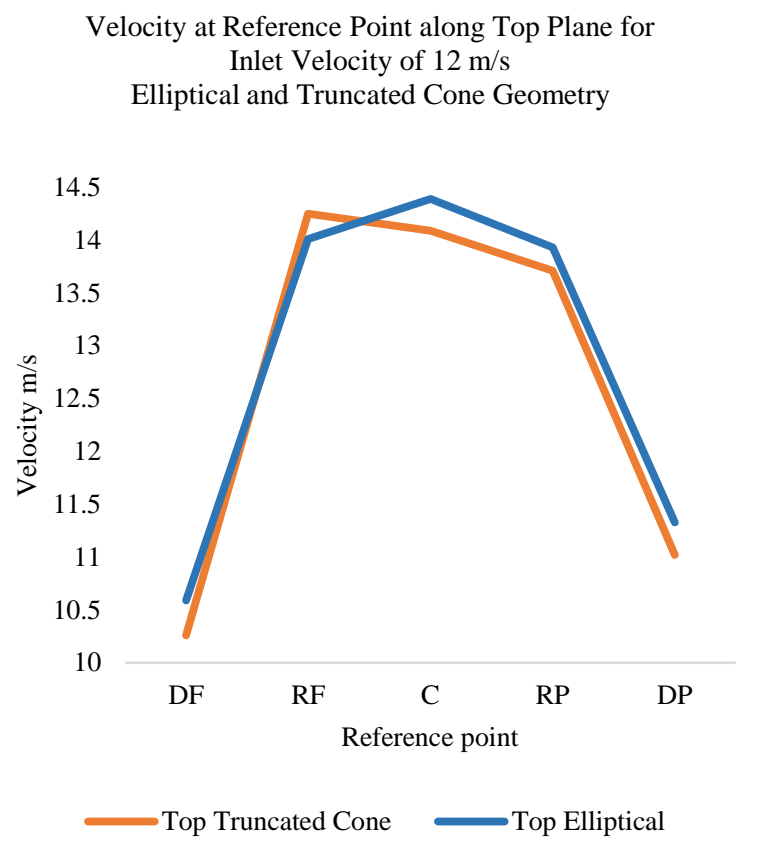

Graph 6 Velocity at each reference point along the top plane for an inlet velocity of $12 \mathrm{~m} / \mathrm{s}$, elliptical and truncated cone geometries

Source: Authors' Own Creation

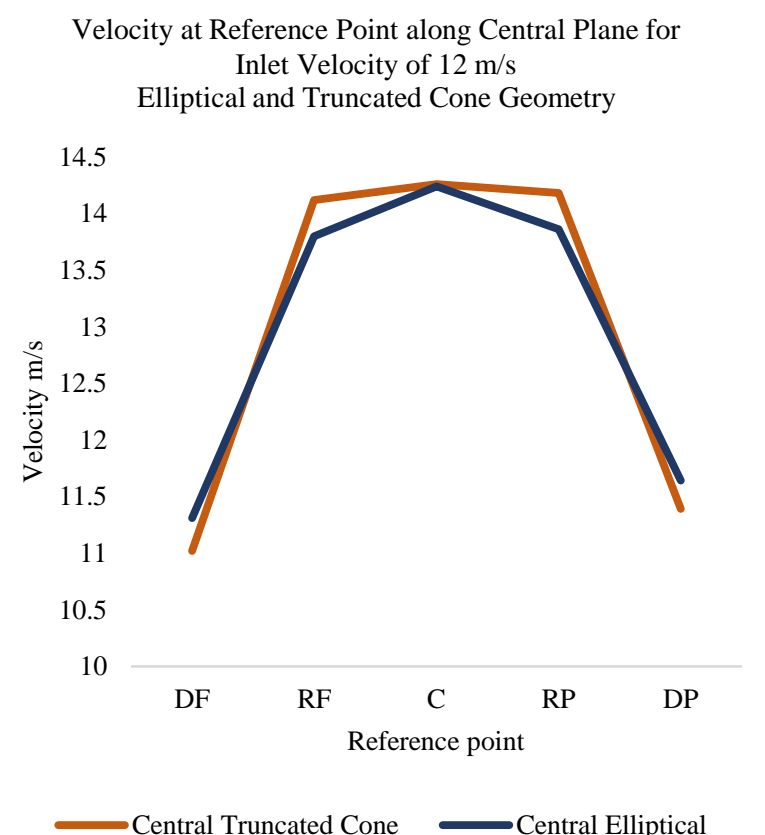

Graph 7 Velocity at each reference point along the central plane for an inlet velocity of $12 \mathrm{~m} / \mathrm{s}$, elliptical and truncated cone geometries

Source: Authors' Own Creation

\author{
Velocity at Reference Point along Bottom Plane for \\ Inlet Velocity of $12 \mathrm{~m} / \mathrm{s}$ \\ Elliptical and Truncated Cone Geometry
}

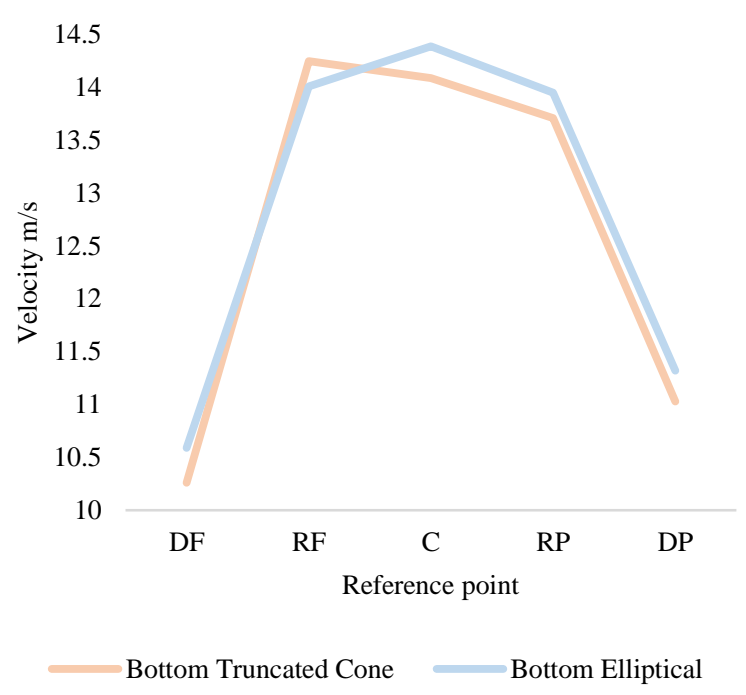

Graph 8 Velocity at each reference point along the bottom plane for an inlet velocity of $12 \mathrm{~m} / \mathrm{s}$, elliptical and truncated cone geometries

Source: Authors' Own Creation

In Graphs 9 and 10, the values of the velocity at points $\mathrm{RD}, \mathrm{C}$, and $\mathrm{RI}$ along the three planes (Graph 9 for top and bottom planes and Graph 10 for central plane) are graphed. Graphs 9-10 are characteristic to the model, since the pattern repeats itself for the other velocities; an inlet velocity of $12 \mathrm{~m} / \mathrm{s}$ was used so that these coincide with the velocity in Figures 10-13. In Graphs 9-10, the symmetry of results between the values along the top and bottom planes can be observed; in addition, another symmetry of results between the left and right sides is also presented and expected, due to the symmetry of the control volume in relation to the plane perpendicular to the lateral face of the geometry.

In Graph 9, the truncated cone presents greater velocities at the edges than in the center along the top and bottom planes. However, in Graph 10, the velocity at the center is greater than those at the edges along the central plane; nonetheless, the difference is small. The elliptical discs in Graphs 9-10 present the similar behavior of possessing a greater velocity at the center than at the edges. Even though the difference between the velocities at the edges and in the center is larger, the elliptical geometry has the advantage of presenting the same behavior along the three planes, while the truncated-cone geometry inverts its behavior along the central plane when compared to the top and bottom planes. 
Velocity at Reference Point along Top and Bottom

Planes for Inlet Velocity of $12 \mathrm{~m} / \mathrm{s}$

Elliptical and Truncated Cone Geometry

14.5

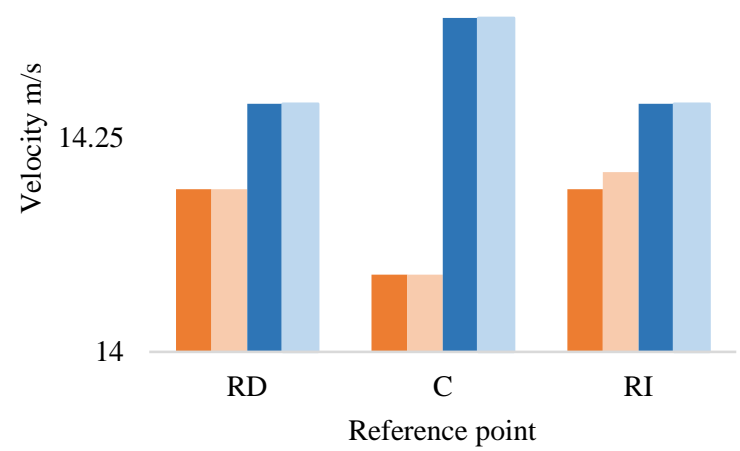

$\square$ Top Truncated Cone $\quad$ Bottom Truncated Cone

- Top Elliptical $\quad$ Bottom Elliptical

Graph 9 Velocity at each reference point along the top and bottom planes for an inlet velocity of $12 \mathrm{~m} / \mathrm{s}$, elliptical and truncated cone geometries

Source: Authors' Own Creation

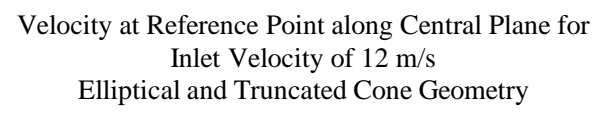

14.5

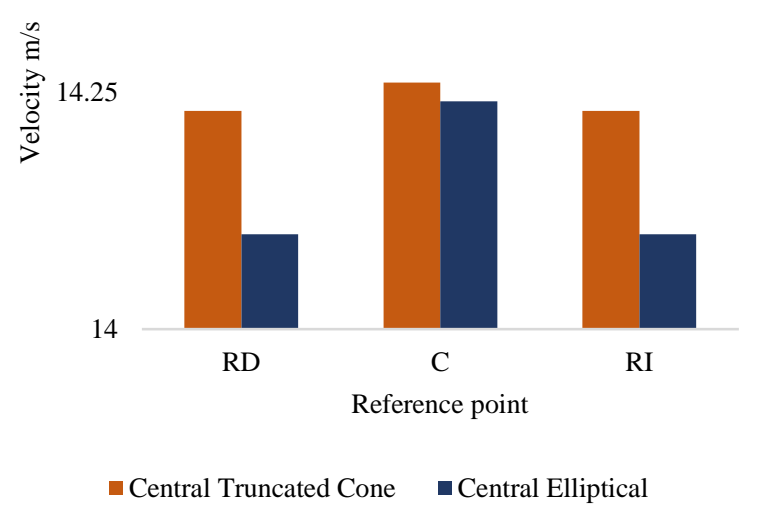

Graph 10 Velocity at each reference point along the central plane for an inlet velocity of $12 \mathrm{~m} / \mathrm{s}$, elliptical and truncated cone geometries

Source: Authors' Own Creation

\section{Acknowledgements}

Our thanks go to the Michoacan University of Saint Nicolás of Hidalgo, and especially to the Mechanical Engineering Faculty, for the facilities provided to develop the present work, as well as to CONACYT for the scholarships granted to Master's students.

\section{Conclusions}

The inductor discs produced a Venturi effect, hence increasing the wind velocity around the rotor area by $15 \%$ compared to the inlet wind velocity. This $15 \%$ rise could be harnessed by vertical axis wind turbines and increase their power generation by up to $50 \%$.

The inductor discs increase wind velocity by producing a Venturi effect; this increase in wind velocity can be harnessed by vertical axis wind turbines to enhance their performance.

The elliptical inductor discs produced a more homogeneous acceleration than the truncated-cone inductor discs, which in turn could result in lower stress on the wind turbine and a lower turbulence, increasing rotor durability and enhancing its performance.

The truncated cone discs have the advantage of further increasing wind velocity in rotor blade areas, compared to the elliptical discs, although the difference is not considerable. However, the concentration zones around the truncated-cone discs increase the possibility of accentuating or increasing turbulence with an operating rotor.

The elliptical inductor discs offer to be the best option as a concentrator, even though its manufacturing could be more complicated due to its shape, compared to the truncated-cone disc.

\section{References}

Burton, T., Sharpe, D., Jenkins, N., \& Bossanyi, E. (2001). Wind Energy Handbook (Jonh Wiley).

García, E. J., \& García, B. (2012). Tesis doctoral Modelización de un captador eólico de alta eficiencia.

GWEC. (2019). GWEC Global Wind Report $2019 . \quad$ https://gwec.net/wpcontent/uploads/2020/08/Annual-WindReport_2019_digital_final_2r.pdf

Hau, E. (2005). Wind Turbines Fundamentals, Technologies, Application, Economics (Springer (ed.); 2a ed.). 
Presses Internationales Polytechnique. (2002).

Wind Turbine Design with Emphasis on Darrieus Concept.

S. Shikha, T.S.Batí, \& D.P.Kpthari. (2003). A new vertical axis wind rotor using convergent nozzles. Large Enginering Conference on Power Energy, 177-181.

Shonhiwa, C., \& Makaka, G. (2016). Concentrator Augmented Wind Turbines: A review. Renewable and Sustainable Energy Reviews, $\quad 59, \quad 1415-1418$. https://doi.org/10.1016/j.rser.2016.01.067

Subsecretaría de Energía Eléctrica. (2019). Energía Eolica. http://www.energia.gov.ar/contenidos/archivos/ publicaciones/libro_energia_eolica.pdf

Yusof, A., \& Mohamed, M. R. (2020). Vertical Axis Wind Turbines: An Overview. Lecture Notes in Electrical Engineering, 632, 821-835. https://doi.org/10.1007/978-981-15-2317-5_68 